\title{
Hydraulics of combining flow in a right-angled compound open channel junction
}

\author{
SUSHANT K BISWAL $^{1, *}$, PRANAB MOHAPATRA ${ }^{2}$ and \\ K MURALIDHAR $^{3}$ \\ ${ }^{1}$ Department of Civil Engineering, National Institute of Technology Agartala, \\ Agartala 799046, India \\ ${ }^{2}$ Department of Civil Engineering, Indian Institute of Technology Kanpur, \\ Kanpur, India \\ ${ }^{3}$ Department of Mechanical Engineering, Indian Institute of Technology Kanpur, \\ Kanpur, India \\ e-mail: drsushantbiswal@gmail.com
}

MS received 1 July 2014; revised 23 July 2015; accepted 7 August 2015

\begin{abstract}
Although combining flows are common in natural streams, no comprehensive experimental data has been compiled to characterize the three-dimensional flow field within the compound channel confluence. The present study examines the time-averaged flow structure at confluence over a rigid bed. Current knowledge of channel confluence, based on laboratory observation indicates that cross flow interactions exert a significant influence on confluence events. Secondary current and turbulent stresses are reproduced well by the hydraulic model and found greater in the interface region as relative flow ratio decreases. Velocity fields in combining flow region arising from varying discharge ratios are presented. A zone of depression in surface elevation in compound channel junction is observed as well. The flow field in compound channel is seen to be moderately different from that of simple channel junction. This study contributes to a better knowledge of hydraulic key processes into fundamental aspect of combining flow dynamics.
\end{abstract}

Keywords. Compound channel; combining flow; velocity field; secondary flows; turbulent kinetic energy; Reynolds shear stress; water surface profile.

\section{Introduction}

River confluences are complex hydrodynamic environments where convergence of incoming flows produces complicated patterns of fluid motion, including the development of large-scale turbulence structures, sediment transport and morphology. Moreover, confluences are important for the ecological connectivity, flood control and water quality. The hydrodynamics as well as the sedimentological and morphological processes in confluence zones are controlled by several variables [1,2], such as the number of adjoining channels, confluence angles, flow discharge in both channels, channel geometry including longitudinal slope and boundary roughness. For flows in an open-channel network, mutual effects exist among the channel branches at a junction. Open-channel junctions are major elements of river networks that play a vital role in the field of fluvial dynamics. This is mainly owing to the numerous numbers of parameter involved and the complex flow features. Therefore it is very important to know the dynamics of combining

*For correspondence flows. It is, however, generally accepted that flow dynamics and mixing at the junction are highly variable both spatially and temporally. The dynamics of confluence are a function of the momentum ratio between the combining flows and the planform geometry of the junction. Due to increase in flow rate and mixing of confluent flows, various zones with a 3D flow pattern having larger turbulence in the junction regime are established (figure 1).

In real case, we are facing different hydraulic conditions to cause changes in channel alignment combining of two flows accompanies many complex problems such as bed scour, bank erosion, the rise of water level, backwater effects and others. In the past, number of researches with different aspects and different viewpoints of hydraulic engineering have been conducted in order to get a greater solution for the certain problems and also to elucidate the flow characteristics, flow mixing and sediment movement at stream confluences. An overview of previous modeling work on experimental, theoretical and the numerical approach for combining open-channel flows is presented as:

Taylor [3] was probably the first researcher to perform theoretical and experimental analyses in channel junctions in 


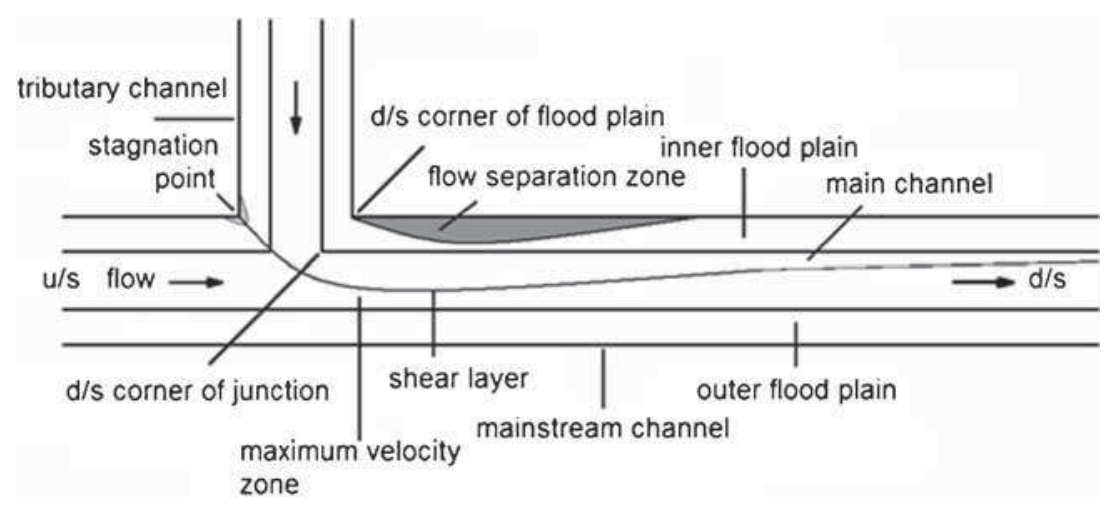

Figure 1. Definition sketch of combining flows in compound open channel.

fluvial regimes, considering junction angles of $45^{\circ}$ and $135^{\circ}$ in an asymmetrical planform. He proposed a 1D approach based on the momentum and mass conservation equations to calculate the ratio between the upstream and the downstream water depths, neglecting the effects of boundary friction and assuming the upstream depth equal to both upstream channels. Following the similar assumption, Webber \& Greated [4] carried out experiments with $30^{\circ}, 60^{\circ}$ and $90^{\circ}$ junction angles, suggesting an empirical correction for Taylor's model. Subsequent to the works of Taylor and Webber and Greated, several authors proposed 1D approaches to estimate the water depths upstream of the junctions for different angles, discharge ratios, channel widths, slope and flow regimes [1, 5-8]. However, the applicability of these 1D approaches was restricted by the 3D hydrodynamic behaviour of junctions. Bradbrook et al [9] demonstrated numerically that secondary circulation can be developed at a channel junction in the absence of planform curvature (parallel channels), under a wide range of combinations of depth and velocity ratios. Then, a large number of numerical simulation confirmed that bed concordance and planform curvature are significant in the formation of the secondary flows in junction regions [10-12]. Huang et al [2] developed a 3D numerical model to investigate the influence of the junction angle on the flow characteristics in open-channel junction flow. Good agreement was obtained between the model simulation and the experimental measurements. Zhang et al [13] derived a 3D numerical model to examine the effect of discharge ratio on the flow characteristics, such as the variation of free-surface elevation and the secondary current at a right-angled open-channel confluence for computing the parameters needed in engineering applications. The results were validated using experimental data of [14] and found to be good. Ghostine et al $[15,16]$ compared the 1D and 2D approaches for subcritical and transitional flows, respectively in channel junctions. The studies were limited to one flow type so no effect of the flow regime was resulted. Later, Ghostine et al [17] extended their previous model to compare both the 1D and 2D approaches numerically for subcritical, transitional and supercritical flows in channel junctions. The results of the numerical simulation indicated that the 1D approach was acceptable for small junction angles and for subcritical and transitional flows. However, the 2D approach gave significantly improved results for all types of flows and arbitrary junction angles. Zeng \& Li [18] developed a hybrid RANS-LES model for the simulation of open channel T-junction flow. The comparison between the computational results and experimental data showed that the hybrid approach was more accurate than RANS in the prediction of turbulence quantities and the mean velocity profiles and water surface elevation in the separation zone of the T-junction flow. Goudarzizadeh et al [19] numerically solved the 3D flow problems at a right angled junction of two rectangular channels using Navier-Stokes equations based on Reynolds Stress Turbulence Model (RSM). The Weber experimental finding (2001) were used to test the validity of data. Comparison of the simulation with experiments indicated a good agreement between the flow patterns of the two sets. It was seen that effects of the flow ratio on geometry of separation zone formed in the main-channel downstream of the junction indicated an inverse relation. Further, Goudarzizadeh et al [20] studied the effect of flow ratio $Q_{r}$ (ratio of tributary to total discharge) and width ratio $B_{r}$ (ratio of the tributary to main-channel width) on separation zone dimensions. Results indicated that the dimensions of the separation zone increase with the flow ratio, however, it reduces with an increase in the width ratio.

Best \& Reid [21] performed an experimental study of junction flows with varying junction angles and discharge ratios. They defined the separation zone shape index $\left(S_{i}\right)$ as the ratio of the width $\left(W_{S}\right)$ to the horizontal length $\left(L_{S}\right)$ of the separation zone at horizontal plane. Where $L_{s}$ is defined as the distance from the downstream corner of the junction to the reattachment point of the flow, and $W_{s}$ is defined by the zero derivative of the streamline passing in the reattachment point. The dimensions of the flow separation zone increase with the flow ratio between the tributary and the main channel and with the junction angle [14, 21]. Best [22] presented a descriptive model of the flow dynamics at the junction based on laboratory experiments conducted in a small flume. The experiments were performed with several 
junction angles and discharge ratios under fixed horizontal bed conditions without sediment transport. His model distinguished six different zones in confluence channels: flow deflection, flow stagnation, flow separation, maximum velocity, shear layer and flow recovery. Field measurements $[23,24]$ demonstrated that the presence of bed discordance between the confluent channels modifies considerably the flows in junction region, and affecting the sediment transport and the bed morphology. In addition, it increases the turbulence intensity in the shear layer and consequently the flow mixing downstream of the junction $[25,26]$. The discharge ratio $\left(Q_{r}\right)$, the momentum flux ratio $\left(M_{r}\right)$, the confluence planform and the junction angles are identified as an important parameters controlling the morphodynamics behaviour of river confluences [10, 27, 28]. Rhoads \& Sukhodolov [29] examined the 3D time-averaged flow structure at three concordant-bed confluence. The authors noted that helical cells can be present in a confluence zone, but claimed that they were not characteristic features of all confluences. Weber et al [14] performed an extensive experimental study of combining flows in a $90^{\circ}$, sharp edged open channel for the purpose of providing a broad data set of three velocity components, turbulence stresses, and water surface mappings. Based on experimental studies, authors pointed out that, under the given flow conditions; the flow field near the bed and near the water surface was different. Hager \& Schwalt [30] performed a laboratory study in a channel junction under supercritical flow condition. Supercritical flow at channel junctions was characterized by a distinct standing wave pattern and described the features and dimensions of three waves. The chocking condition and breakdown of junction were also discussed. Liu [31] and Wang et al [32] executed an experiment in open channel junction flows and conceded that the geometric features of the separation zone were of 3D characteristics, in particular along the flow depth with sharp change. Mignot et al [33] described the flow structures that occurred in a $90^{\circ}$ junction of four open channels with supercritical flow in two orthogonal inlet channels. An experimental facility was constructed to permit the measurement of flow rates, water depth and the position of hydraulic jump in the channel. The author reported that various flow patterns which appeared depend on the characteristics of the incoming flows and the location and shape of jump. They suggested a relationship between the location of hydraulic jump and momentum ratio, $M_{x} / M_{t}\left(M_{x}\right.$ momentum in $x$-direction, $M_{y}$-momentum in $y$-direction, $\left.M_{t}=M_{x}+M_{y}\right)$ but it was not clear whether this relationship can be generalized beyond the conditions studied in the experiment. Based on experimental observations, Yang \& Wang [34] presented the detailed characteristics of the separation zone using streamline method. The authors defined that the downstream edge of the junction is considered as the starting point of the separation zone and the point where the streamline normal to the boundary surface is taken to be the end of separation zone. The flow distribution in a four branch intersection was studied experimentally for subcritical flow by [35]. The results were used to establish a relationship between the incoming flow rates and the flow distributions in two outlet channels, based on the conservation of discharge and momentum at the intersection. The stage discharge relationship for the downstream control in the outflow channels was also presented.

Based on the above discussion, it is found that several studies on combining flow in simple open channel have been reported in literature. However, the analysis of 3D flow at a compound open channel junction is still limited. Therefore, the present study is concerned with the problem of combining flow in a compound open channel using a laboratory approach under clear water condition without feeding sediment. The results obtained by means of systematic experimental investigation carried out in a confluence flume are not simulated or compared with field data, however provides a basis for advancing fluvial process based on observed differences in time-averaged flow structure between simple and compound channels. Special attention is given to the flow from the tributary channel and its effect on the hydrodynamics processes in the junction region. The main objectives of this study are:

- To understand flow mixing, secondary flow pattern, and backwater effects in a rigid boundary compound channel junction

- To assess changes in surface elevation that occurs during flow at a junction

- To examine how the structure of three-dimensional flow varies with changes in the ratio of flow rate between the two confluent streams

- To discuss the influence of flow ratio on the flow dynamics

- To provide detailed experimental data on the 3D flow field that is essential for the validation of numerical models.

The studies mentioned above provide insightful information for understanding of the flow and assist engineering design of open-channel junctions.

\section{Experimental facility and equipment}

Schematic diagram of experimental setup for subcritical flow is shown in figure 2. The physical model is made of brick masonry with smooth rigid bed. The combining compound channel consists of mainstream channel (main channel and floodplain) and tributary channel (tributary and flood plain). The lengths of the mainstream and the tributary channel are $14.6 \mathrm{~m}$ and $3.45 \mathrm{~m}$, respectively. Both channels are of equal bottom width, $B=0.20 \mathrm{~m}$. The channel bottom is located at a depth of $0.10 \mathrm{~m}$ from the floodplain and the width of each floodplain is $0.30 \mathrm{~m}$. Keeping in mind, the characteristics of roughness in natural streams, the top surface of the floodplain and the main channel of the physical 


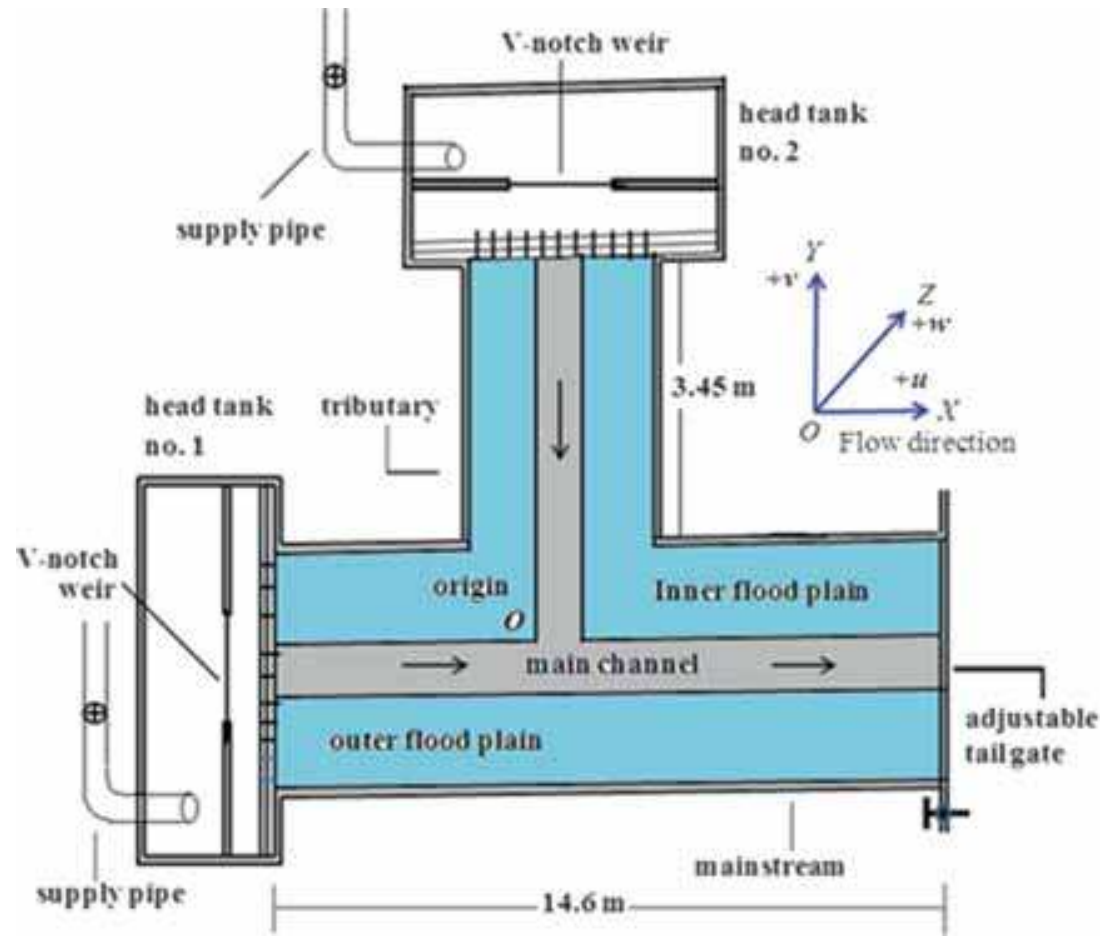

Figure 2. Schematic diagrams representing experimental setup for combining flows in compound open channels.

model are plastered using 1:6 cement sand mortar. Further, the top of the main channel bed is smoothed by a thin layer of cement slurry and polished by using exterior oil weather paint. The effect of roughness on flow behavior is not systematically evaluated. Water is discharged from two independent upstream constant head tanks which are controlled by gate valves attached to each tank. Pre-calibrated right-angle V-notch is provided at each channel inlet to measure the rate of flow. Sets of honeycomb structures are placed at the entrance of both channels to ensure low disturbance parallel flow entering the channels. The origin of the coordinate system ( $X$ is along channel length; $Y$ is along lateral direction and $Z$ is along the vertical) is the bed at the upstream corner of the channel junction. The dimensionless coordinates $X^{*}, Y^{*}$ and $Z^{*}$ are obtained by using main channel width, $B$, as the reference scale. Water surface elevations are measured by a point gauge with an accuracy of $\pm 0.1 \mathrm{~mm}$, the results of which are compared with the timeaveraged flow depth by using water surface profiler [36]. An acoustic Doppler velocimeter (ADV) with an accuracy of $\pm 0.5 \%$ of the measured value is used to measure the velocities at selected cross-sections. Velocity measurements at each location of upstream and far downstream from the junction are taken for $120 \mathrm{~s}$ at a sampling rate of $50 \mathrm{~Hz}$. However, for the flow data recorded near the junction region, the effect of combining flow is predominant and a sampling rate of $50 \mathrm{~Hz}$ is used for duration of $180 \mathrm{~s}$. The software package WinADV for post-processing of ADV data is used to compute the time-averaged values of downstream $(U)$, cross stream $(V)$, and vertical $(W)$ velocity for the point measurements. The velocity measurements have been nondimensionalized by the average cross-sectional velocity at outlet, $U_{d}$. The time series of velocity at each sampling point is used to produce a time-averaged velocity which is used for further analysis. The flow depth at the outlet, $h_{\mathrm{d}}$ of the downstream branch channel relative to main channel bottom is controlled by an adjustable tailgate. A series of runs with varying inflow discharges are conducted in this study (table 1). For the purpose of velocity measurements, each compound channel cross section is divided into five evenly spaced vertical profiles on main channel and eight evenly spaced vertical profiles on each floodplain (figure 3 ). The grid has 4,650 velocity measurement locations for each flow condition studied.

The inflow discharge in the mainstream, tributary and combined outflow discharge at the downstream branch channel are denoted as $Q_{m}, Q_{t}$ and $Q_{d}$, respectively. The discharge ratio, $Q_{r}$, is defined as the ratio of the inflow discharge, $Q_{m}$, to the outflow discharge, $Q_{d}$, of the mainstream channel. In this study, $Q_{d}=0.016 \mathrm{~m}^{3} / \mathrm{s}, h_{\mathrm{d}}=0.22 \mathrm{~m}$, and

Table 1. Flow parameters employed in the branched compound channel experiments.

\begin{tabular}{lcccc}
\hline Cases & $Q_{m}\left(\mathrm{~m}^{3} \mathrm{~s}^{-1}\right)$ & $Q_{t}\left(\mathrm{~m}^{3} \mathrm{~s}^{-1}\right)$ & $Q_{d}\left(\mathrm{~m}^{3} \mathrm{~s}^{-1}\right)$ & $Q_{r}=\frac{Q_{m}}{Q_{d}}$ \\
\hline 1 & 0.012 & 0.004 & 0.016 & 0.750 \\
2 & 0.011 & 0.005 & 0.016 & 0.687 \\
3 & 0.008 & 0.008 & 0.016 & 0.500 \\
4 & 0.005 & 0.011 & 0.016 & 0.324 \\
5 & 0.004 & 0.012 & 0.016 & 0.250 \\
\hline
\end{tabular}



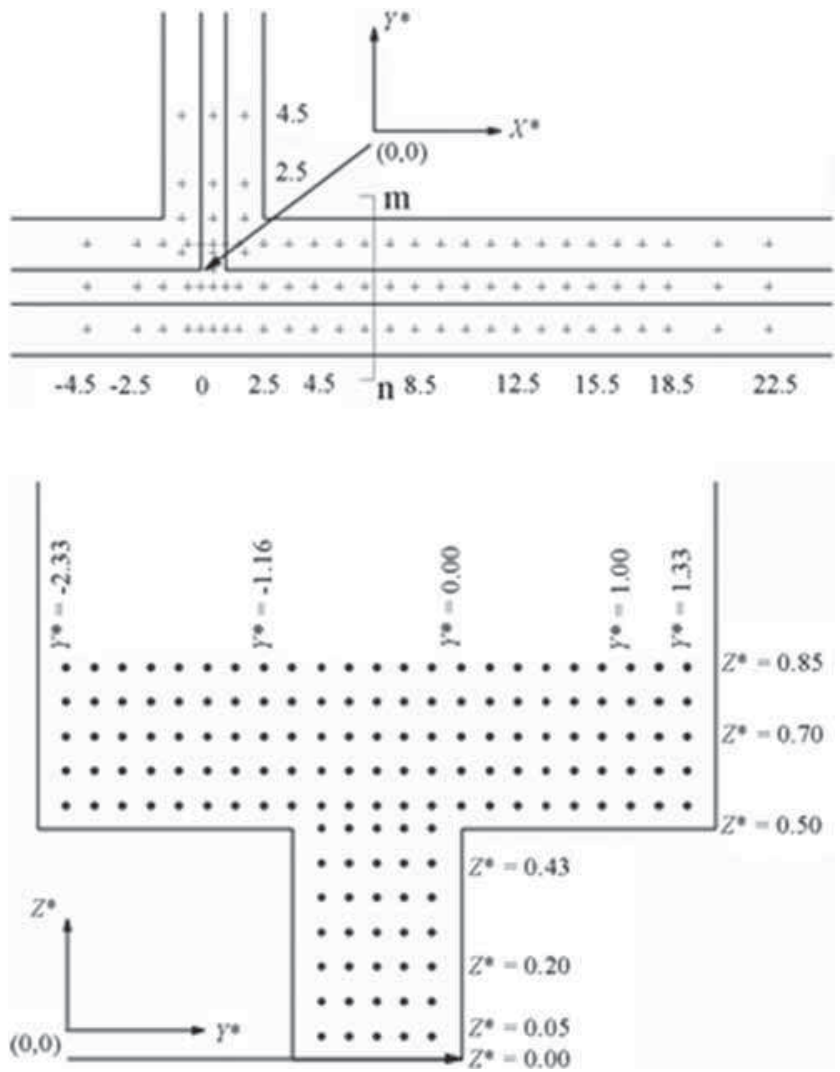

Figure 3. Top view of the channel where locations of velocity measurements are shown by the + sign. Point $\mathrm{O}$ is the origin of the coordinate system. (b) Points of velocity measurement at section $\mathrm{m}-\mathrm{n}$ of the combining compound open channel.

$U_{d}=0.138 \mathrm{~m} / \mathrm{s}$ are held constant for all the experiments. The non-dimensional parameter such as Froude number Fr (0.07 0.21) and Reynolds number $\operatorname{Re}(13,508 \sim 59,438)$ of the combining compound channel are varied during experiments and are obtained at three different locations, namely both the upstream channel, the junction point and near outlet of the combining compound channel. Observations for velocity and surface elevation have been recorded under identical flow conditions.

\subsection{Validation}

Results for simple combining channels obtained in the present set of experiments are validated against the experimental results reported in the literature [6]. The physical model of the combining compound channel geometry is interpreted as two separate simple open channel junctions of $0.20 \mathrm{~m}$ and $0.80 \mathrm{~m}$ widths. It is signified in figure 4 that the depth ratio, $D_{r}$, is reported as a function of $Q_{r}$. The present experimental results match satisfactorily with the results obtained by [6] for both the channel widths used in the present study. Comparing the present results with those obtained by [6], the maximum relative errors in the smaller

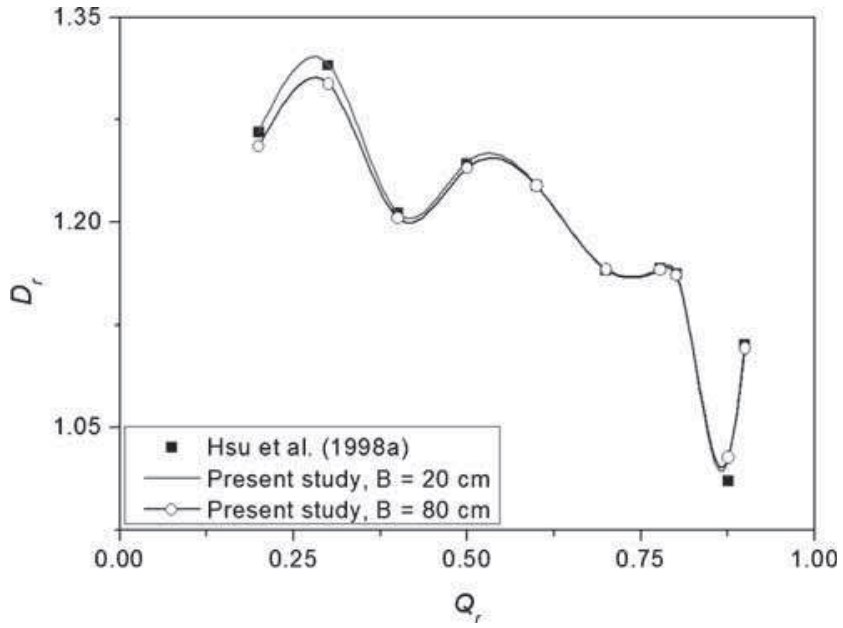

Figure 4. Validation of the experimental apparatus: Depthdischarge relationship in simple combining channel.

(wide $=0.20 \mathrm{~m})$ and in the larger $($ wide $=0.80 \mathrm{~m})$ channels are $0.5 \%$ and $0.3 \%$, respectively.

\section{Results and discussion}

Data generated from experiments are verified for repeatability, and the results of this work are presented below in the following sequence: velocity vectors, secondary currents, turbulent kinetic energy (TKE), Reynolds shear stress (RSS) and water surface profile.

\subsection{Velocity vectors}

The presence of the confluence causes considerable redistribution of the main channel flow. The secondary motion in the combining channel flows is influenced by cross flow from tributary and mass exchange at the interface between two confluent streams. Due to lateral momentum transfer across the interface, secondary motion in the mainstream channel is setup that rotate against the secondary motion of the tributary channel. Thus, a zone of turbulence is created close to the upstream junction, and it expands further into the tailwater channel. A separation zone is set up along the wall adjacent to inner floodplain of the tailwater channel immediately downstream of the junction (figures 6-7). It results due to the momentum of the tributary flow causing the main flow to detach at the downstream corner of the junction. The formation of separation zone reduces the effective flow area and causes flow acceleration. Additionally, it is a region of low pressure and recirculating flows, commonly associated with the accumulation of fine sediments [21,37]. The presence of separation pushes the flow to the right bank when looking downstream, which produces the maximum $u$ velocity in the flow region. The situation is similar to a gradual channel constriction with subcritical flow upstream, where the flow velocity and Froude number increase as the flow 
passes through the constriction. It is noted that the velocity outside the separation zone is very high due to the separation. Particularly, the high velocity stream is penetrated to the bed for the low discharge ratio which could be a major concern in the erodible channel junction design. In case of mobile bed, this flow acceleration is generally associated with the increase of bed shear stresses and consequently with sediment transport. The sediment deposition near the inner bank attains its maximum height, which leads to a considerable reduction of the flow cross-section in the post-confluent channel. Similar behaviour has been observed by [38] in small natural bed concordant confluences.

In this study, a constricted region is formed nearby separation zone in the tailwater channel at $X^{*}=5$ which carries higher velocity of magnitude $u=0.298 \mathrm{~m} / \mathrm{s}$ (i.e. $u^{*}=2.16$ ). This effect may be attributed to the entrance angle of tributary flow. At approximately $X^{*}=6.5$, nearly $65 \%$ of the channel width conveys flow downstream near the floodplain compared to $54 \%$ of the channel width for the surface flow. This value was approximately equal to $55 \%$ near the surface in the experiments of [14]. The differences in the lengths of the separation zone are clearly evident when the surface and floodplain at section $X^{*}=9.5$ are compared. Far downstream, velocities in the floodplain gradually diminish and a nearly uniformly distribution on the surface is obtained.

Figures 5-7 shows the flow patterns of time-averaged streamwise velocities at three elevations, namely the bed, the floodplain and on the surface in a compound channel junction for $Q_{\mathrm{r}}=0.25$ and 0.50 . The vector fields illustrate that the entrance condition of the tributary flow is significantly different between the floodplain and the water surface. However, there is no discernible effect of the tributary flow on the bed of the mainstream channel, because its angle of entry to the mainstream results in negligible lateral momentum exchange at the bed. It is clearly seen in figure 5 that the velocity field at the bed is more uniform across the channel towards downstream and skewed slightly at the upstream corner of the junction with the tributary due to backwater effect.

It is examined that the all longitudinal velocity patterns near the bed are distinctly different from the near surface velocity patterns. Further, comparing the angle of entry of the flow from the tributary, the surface flow enters at a larger angle to the mainstream channel than that at the floodplain level. The smaller angle of entry is due to lower lateral momentum flux at the floodplain. The velocity vector field in terms of its velocity components in the horizontal plane gives insight into the differences between the floodplain and the surface momentum of the flow entering the mainstream channel. It is noticed that the developed flow has higher velocities near the water surface and provides an increased momentum over that near the floodplain. The result of this momentum difference causes variation in the amount of deflection towards the downstream direction of the branch fluid. As a result the velocity patterns, separation zone, and zone of recovery are considerably altered between the floodplain and the water surface. The geometry of the separation zone varies gradually in a vertical plane. The values of shape indices, $S_{i}$, at the floodplain and close to water surface are nearly equal to 4.47 and 4.86 respectively for $Q_{r}=0.5$. This feature is magnified with a reduction in the discharge ratio $Q_{r}$. Earlier studies did not address this occurrence that the length of the separation zone
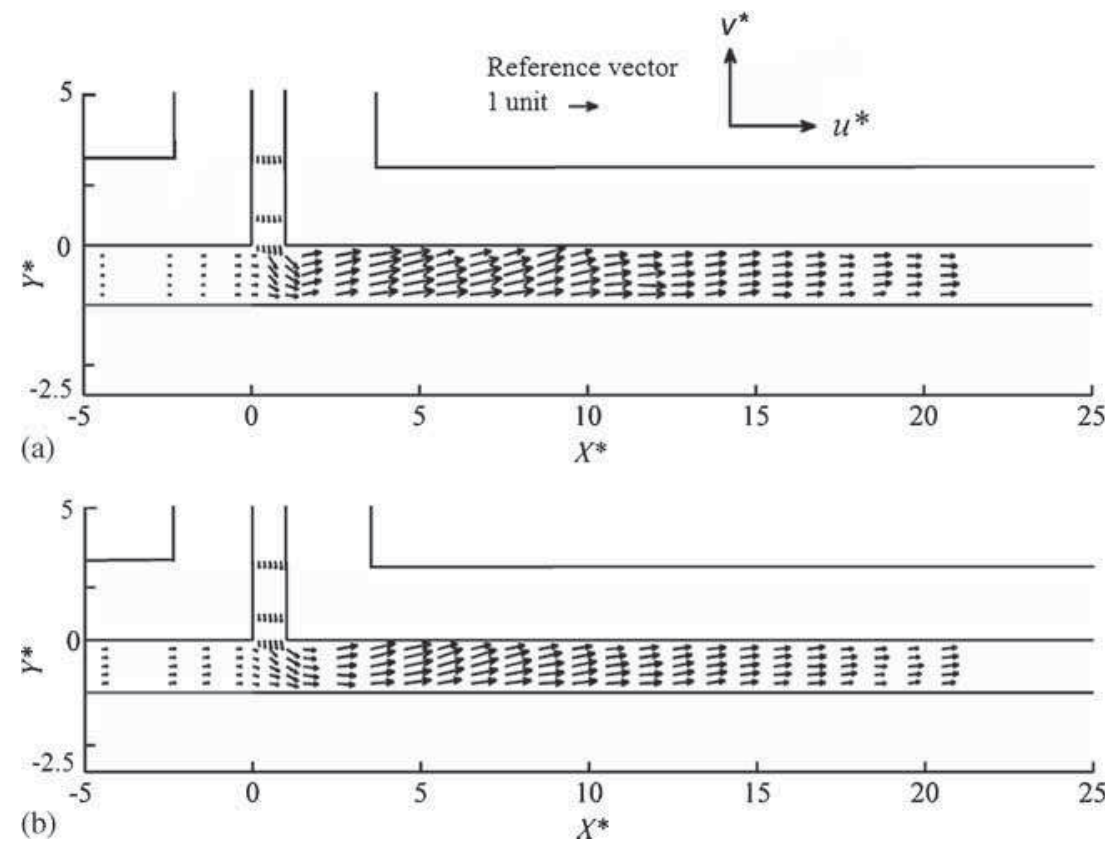

Figure 5. Velocity fields close to the bed level $Z^{*}=0.05$ in a combining compound channel for flow conditions (a) $Q_{r}=0.25$ and (b) $Q_{r}=0.50$. 

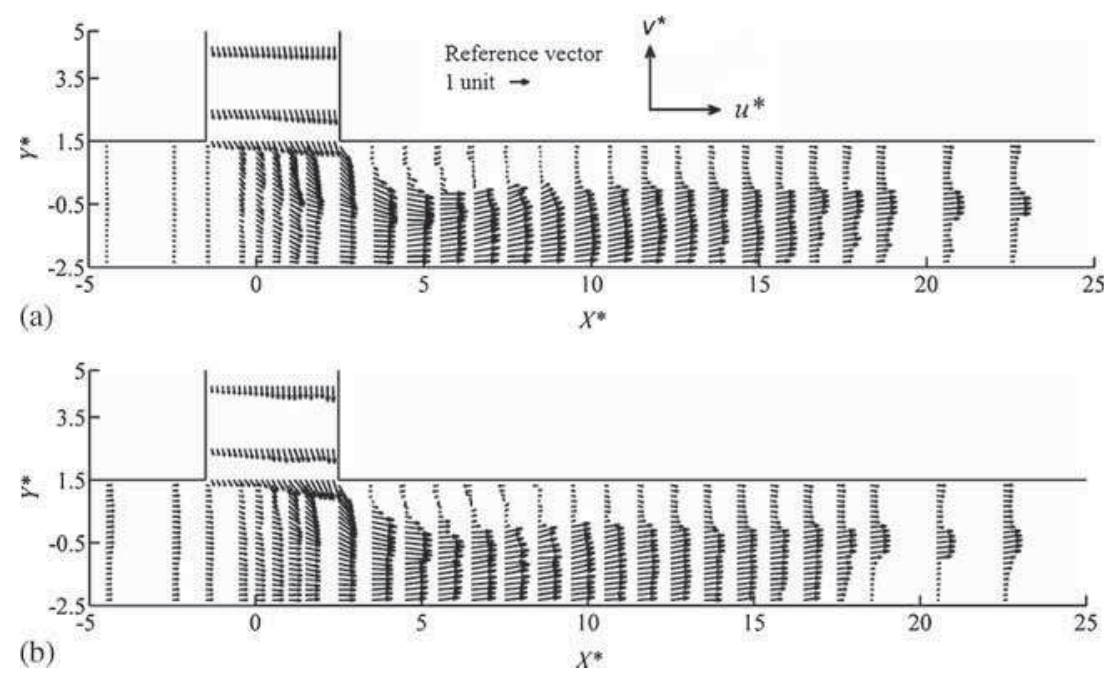

Figure 6. Velocity fields close to the floodplain level $Z^{*}=0.55$ in a combining compound channel for (a) $Q_{r}=0.25$, (b) $Q_{r}=0.50$.

continually increases as discharge increases from the tributary channel. The $u^{*}-v^{*}$ vector fields for various values of the discharge ratios reveals the following.

The difference between the entrance angles near the bed and the floodplain compared to the water surface for the tributary is smaller when the discharge ratio, $Q_{r}$ is higher. The drift of the maximum streamwise velocity below the free surface due to the secondary currents in the mainstream becomes less pronounced. The velocity vectors in the mainstream for higher $Q_{r}$ show less deflection towards the outer wall through the junction region. The velocity field at the channel bottom is more uniform across the channel section for all $Q_{r}$ values, when compared to both the floodplain and the surface.

\subsection{Secondary currents}

Figure 8 shows the vector description of time-averaged secondary currents $\left(v^{*}, w^{*}\right)$ in the vertical plane as flow evolves downstream from $X^{*}=3.5$ to $X^{*}=22.5$. The vector plot shows the surface water approaching the outer wall at $X^{*}=$ $3.5, Y^{*}=-2.5$. It is a result of the lateral momentum being greater near the surface compared to the region near the bed. Since the wall is impermeable, the surface water is deflected in the downstream direction by the oncoming mainstream water. The $v^{*}$-velocity component gradually diminishes as flow progresses in the downstream direction. The first portion of the junction flow to enter the separation zone along the inner wall adjacent to junction is the near bed flow owing to the negative $v$-component of flow. Loss of kinetic energy in the converging flows, especially in the

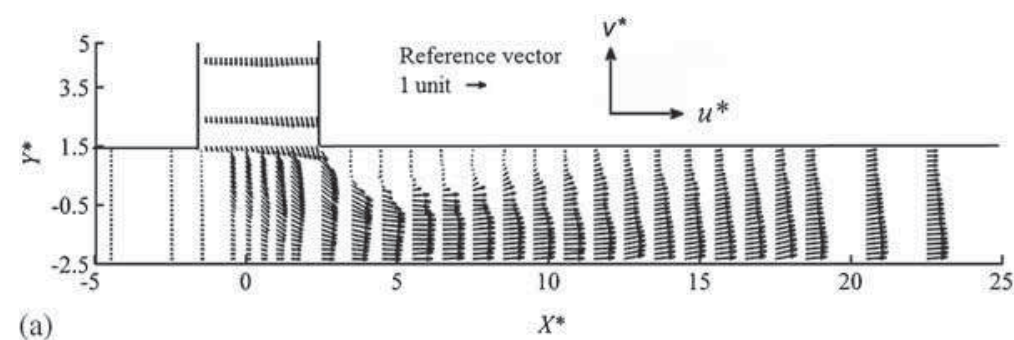

(a)

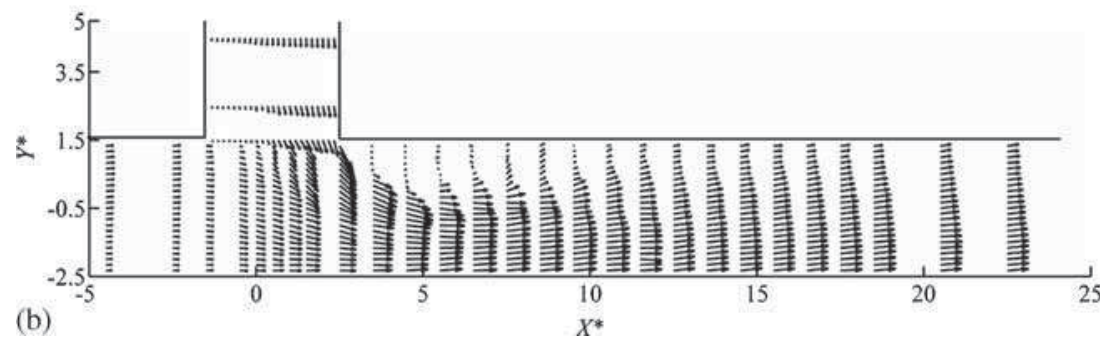

Figure 7. Velocity field near the water surface for (a) $Q_{r}=0.25$, (b) $Q_{r}=0.50$. 


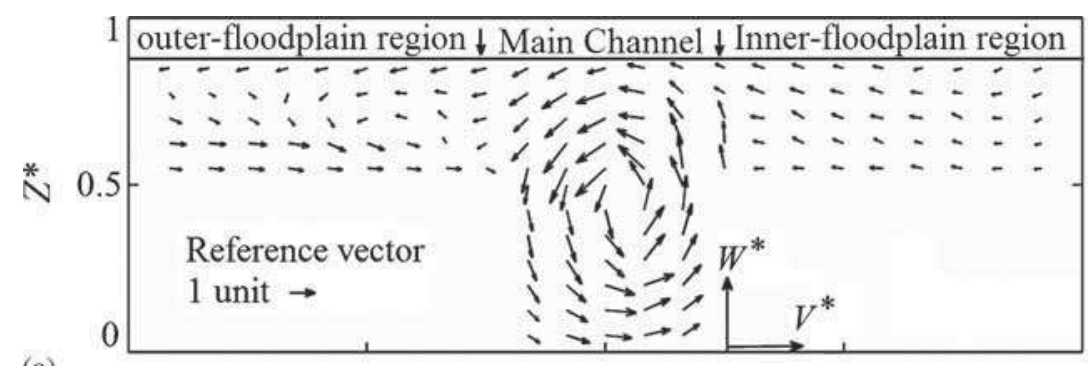

(a)

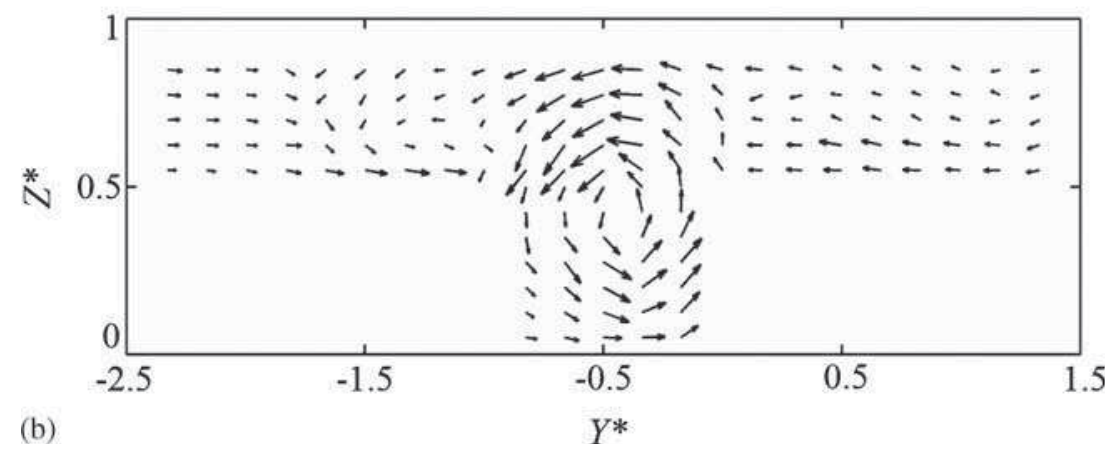

Figure 8. Velocity vectors of secondary currents at $X^{*}=4.5$ for (a) $Q_{r}=0.25$, (b) $Q_{r}=0.50$.

region near the junction where low velocity fluid along the channel banks meets, produces an increase of pressure and superelevation of the free surface [39]. The raised free surface elevation induces vortical motion of fluid toward the bed. As flow approaches the bed, it moves laterally away from the mixing interface toward each bank and then upward toward the surface. This motion creates a shear layer that develops along the interface of two merging flows. This phenomenon is similar to the surface flow at the outer bank where flow is deflected in the downstream direction. With a higher rate of inflow mixing near the junction within the shear layer, it can be seen that, a large anticlockwise secondary current develops in the scale of flow depth along the channel interface. Huang et al [2] and Bradbrook et al [39] observed the similar results in the simple channel junction and reported that the strength of the secondary flow increases with the junction angle. In the present study, the strength of secondary current depends mainly on the momentum ratio between the two confluents and the maximum magnitude of $V s=\left(v^{2}+w^{2}\right)^{0.5}$ is about $22.7 \%$ of $U_{d}$, the average cross-sectional velocity.

Although the mechanism of generation of secondary currents is quite complicated, the anisotropy between $v^{\prime}$ and $w^{\prime}$ is the main cause of their occurrence. Where the turbulence is anisotropic and close to the free surface, the velocity field is significantly affected by the eddy viscosity. Such anisotropy of turbulence is related to the difference in boundary conditions between the solid boundaries and the free surface. For subcritical flows (small Froude number) the free surface is not deformed and the normal turbulent stress, $\overline{w^{2}}$ confronts a limiting boundary and is redistributed to the horizontal components $\overline{u^{2}}$ and $\overline{v^{2}}$. As a result, the anisotropy of turbulence increases, affecting greatly the secondary flow patterns and thus the streamwise velocity distributions. It is observed that the secondary currents at $X^{*}=16.5$ have substantially diminished. However, the 3D nature of the channel junction flow diminishes greatly as discharge ratio, $Q_{r}$ increases. Because the secondary flows at channel junction is more complex and less organized (see figure 8), no attempt has been done in this study to quantify it analytically. The numerical model of [2] predicts the flow patterns well and the positions of vortices correctly. However, the strength of vortices seems to be underpredicted.

\subsection{Turbulent kinetic energy (tke)}

The confluence enhances turbulence activity, which is relevant with respect to the mixing of the mass and the momentum coming from the mainstream and the tributary channel. The increased turbulence activity may be attributed to two processes. First, the collision of the flows originating from both channels creates a shear layer that is characterized by increased turbulence activity. Second, the momentum input by the tributary flow increases the magnitude of the velocities in the junction region and consequently the turbulence activity; since turbulent kinetic energy (tke) scales with the square of the mean velocity magnitude. The turbulence is mainly induced by bottom friction and redistributed in the cross-section by the turbulence-induced helical flow cells that cause transverse variations in the tke [40]. Turbulent kinetic energy represents the energy extracted from the mean flow by motion of the turbulent eddies. In the present study, the experimental data can be used to identify the mechanism of production of tke in open channel junction flows over a smooth rigid bed. Turbulent kinetic energy is resulted 
from shear in the time-averaged base flow originating from both channels. It is calculated from the acoustic Doppler velocimeter $(\mathrm{ADV})$ data, since the $\mathrm{ADV}$ provides time series of the three components of velocity fluctuations. Turbulent kinetic energy, $K$ is calculated as the sum of the mean square of velocity fluctuations and is defined as

$$
K=\frac{1}{2} \rho\left[\left(\overline{u^{\prime 2}}\right)+\left(\overline{v^{\prime 2}}\right)+\left(\overline{w^{\prime 2}}\right)\right]
$$

where $\overline{u^{\prime 2}}, \overline{v^{\prime 2}}, \overline{w^{\prime 2}}$ are the mean square values of the fluctuations in velocity in the streamwise, cross-stream and vertical directions respectively. Figure 9 shows a contour plot of the normalized values of $K^{*}$ with $X^{*}$ for $Q_{r}=0.25$ and 0.50 . Turbulent kinetic energy is normalized with respect to the square of the total average discharge in the apparatus $U_{d}^{2}$. It is noted that, while the tributary discharge is impinging on the main channel discharge, both flows pass through the channel junction without significant mixing between the two flows. However, significant turbulence occurs as the higher velocity flow of the main channel begins to mix with the lower velocity flow of the tributary channel in the separation zone downstream of the junction. As turbulence development is sensitive to the strength of the secondary flows. The magnitude of turbulence increases owing to the large contribution of secondary flows on momentum transport. The increase in percentage of turbulent energy of the fluid particles with a reduction in discharge ratio influences the nature of the flow features. It is observed that the peak tke values occurred within the mixing layer interface. McLelland et al [41] also marked a zone of high turbulent kinetic energy very well within mixing layer in both laboratory and natural channel confluences. In this study, non-dimensional values of TKE were 4-5 times larger than those [41] observed at a natural braided confluence in the Sunwapta River. In a study of a confluence with a discordant bed, De Serres et al [42] reported that the peak tke values occurred on the sides of the mixing layer interface rather than close to the center of
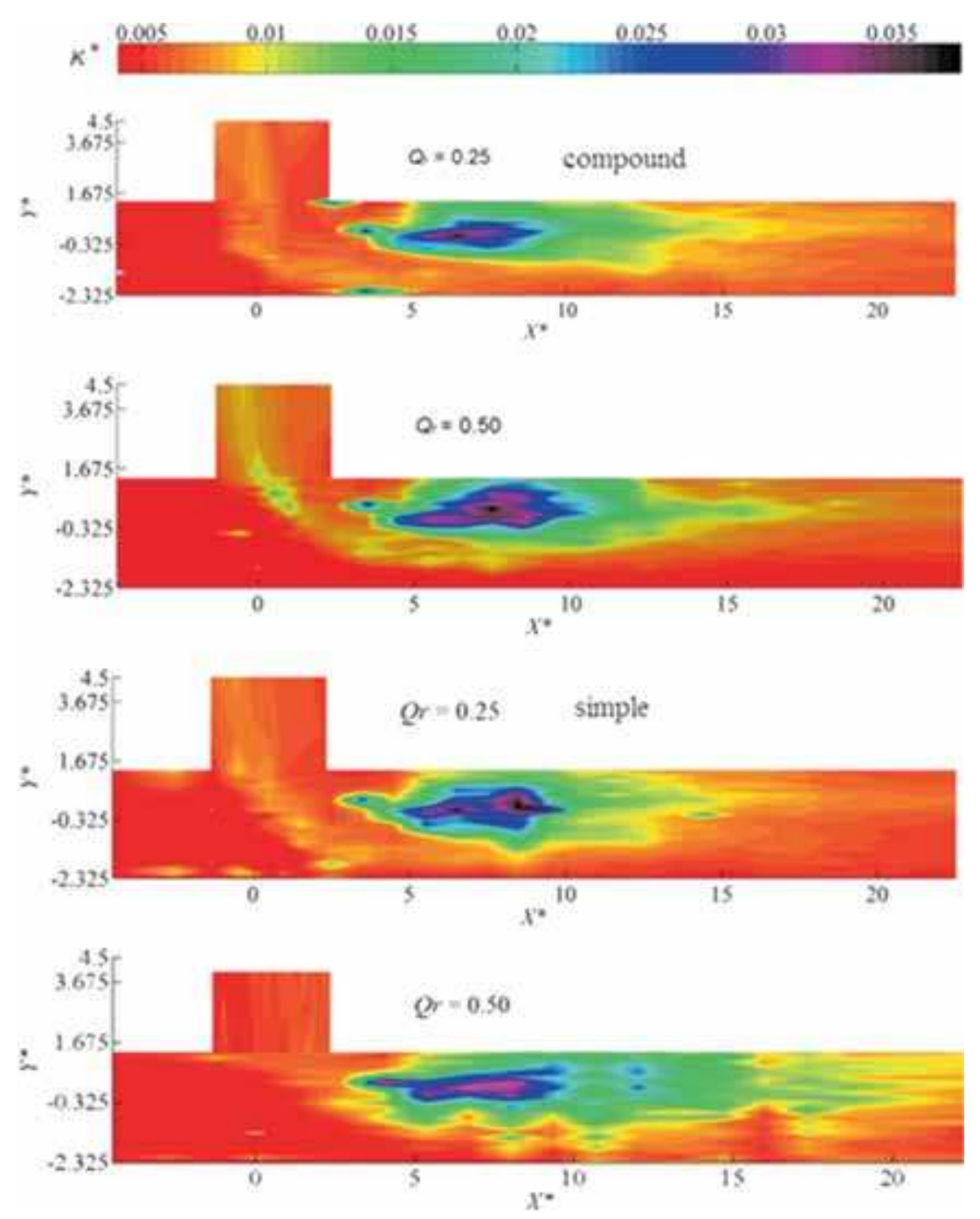

Figure 9. Non-dimensional turbulent kinetic energy near the water surface for $Q_{r}=0.25$ and 0.50 in combining compound and simple channel. 
mixing layer interface. De Serres et al [42] have shown that the turbulence intensity (defined as the RMS of the fluctuations in velocity divided by the maximum downstream velocity for each hydrological event) remains high over the entire water column in the shear layer region. The magnitude of RMS $\mathrm{u}$ in relation to RMS $\mathrm{w}$ is not constant throughout the confluence. For points outside the shear layer, RMS $\mathrm{u}$ is always higher than RMS w, whereas inside the shear layer the situation is reversed. Generally, the peak in tke occurred near the junction. This indicates that the generation of turbulence is greatest where mixing begins to take place and where instantaneous lateral gradients in velocity and pressure between the two streams may be expected to be highest. It is found that the transverse velocity fluctuation $v^{\prime}$ becomes dominant near the wall region. The patterns of turbulent velocity fluctuation $v^{\prime}$ and $w^{\prime}$ is quite different in this region indicating turbulence anisotropy. It is estimated
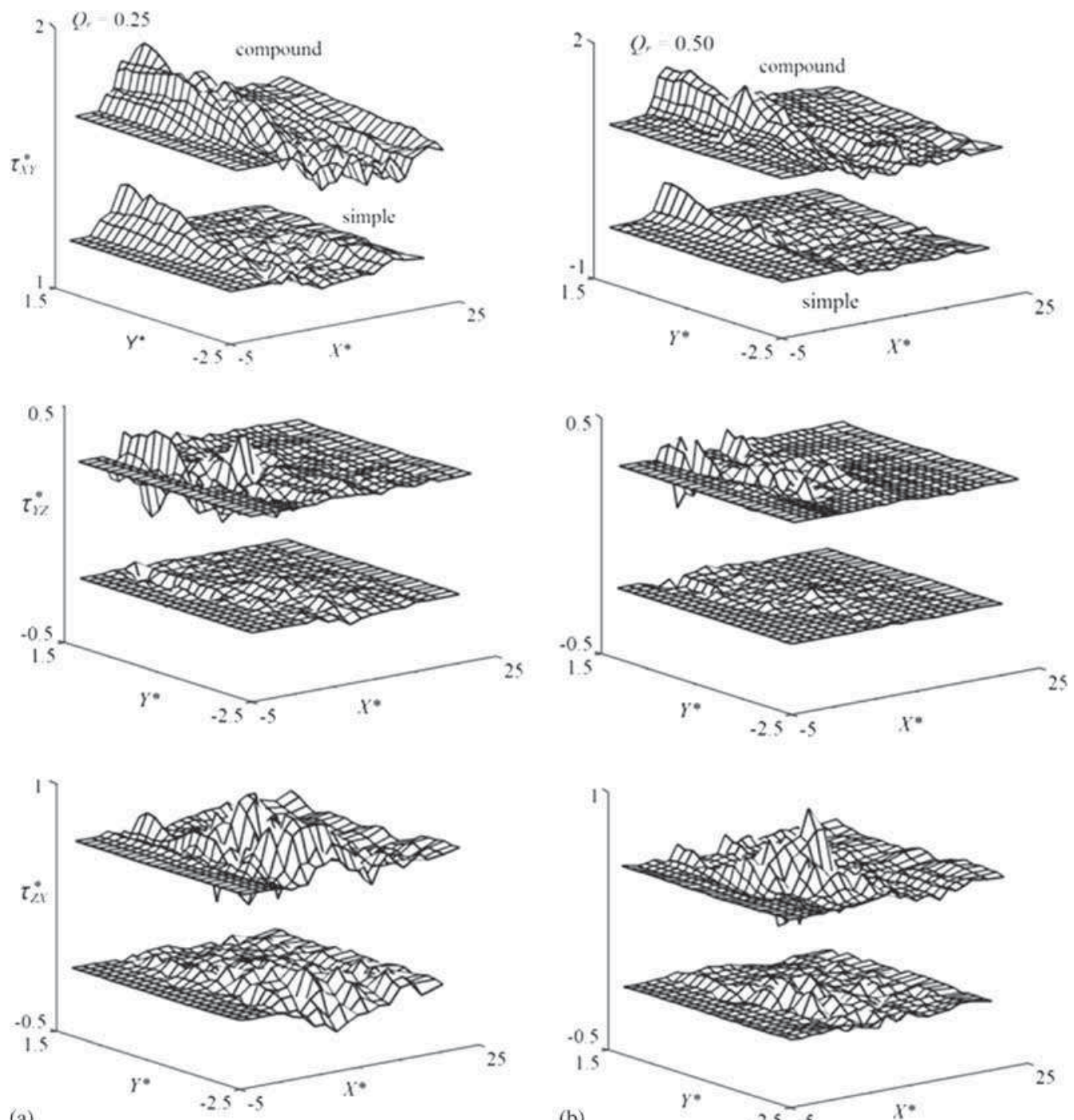

(a) that around $62 \%$ and $38 \%$ of additional energy is generated in compound and simple channel junction respectively for a discharge ratio of $Q_{r}=0.25$ in the near field close to the shear layer when compared to $Q_{r}=0.50$. The results show that the tke in compound channel junction is slightly higher than the simple channel junction near the surface at the point of maximum turbulence region for two flow conditions (i.e. 0.25 and 0.50 ). It is also stated that the minimum value of streamwise turbulent energy appears not on the free surface but below it. This feature corresponds well with the velocitydip phenomenon, observed in narrow rectangular channels [43].

\subsection{Reynolds shear stress (RSS)}

Figure 10 shows the distributions of non-dimensional RSS in isometric form for two flow condition $\left(Q_{r}=0.25-1^{\text {st }}\right.$
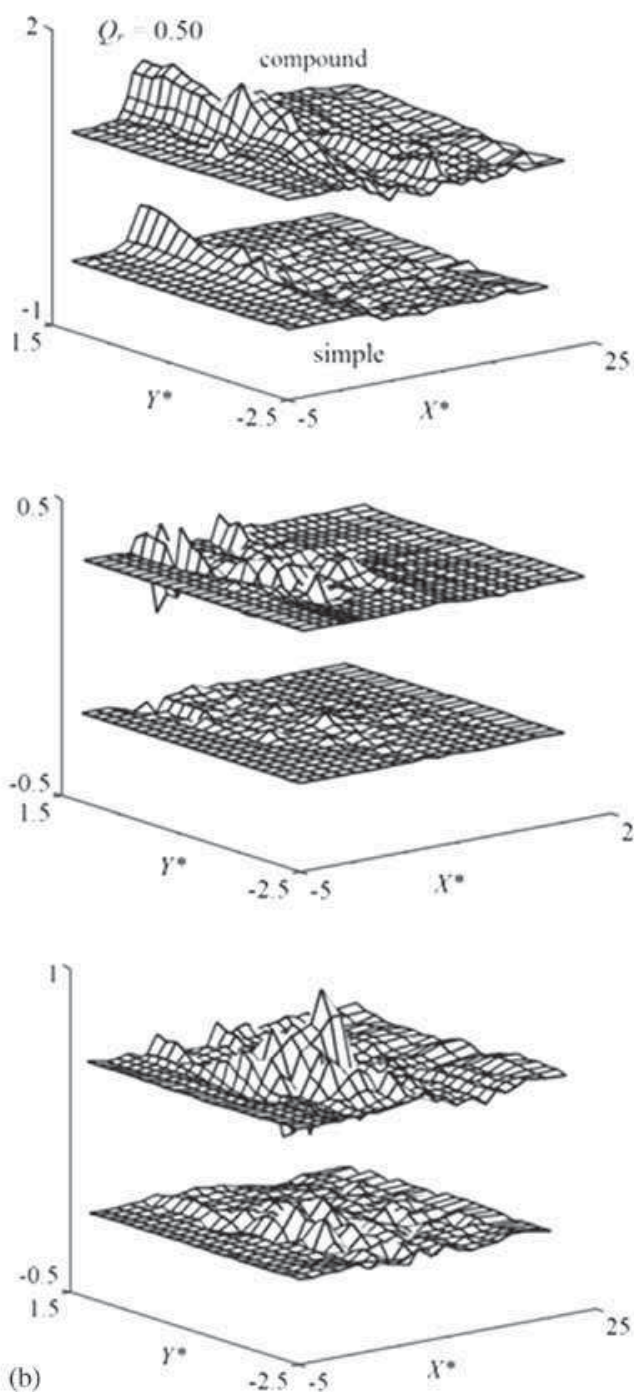

Figure 10. Distributions of the non-dimensional Reynolds shear stresses for two flow conditions $\left(Q_{r}=0.25-1^{\text {st }}\right.$ column and $0.50-$ $2^{\text {nd }}$ column) in open channel junction near the water surface. The main flow direction is $X^{*}$, while the tributary flow is oriented in the negative $Y^{*}$ direction. The center lines of the two channels meet at $X^{*}=0.5$ and $Y^{*}=-0.5$. 
column and $0.50-2^{\text {nd }}$ column) in open channel junction near the water surface. Reynolds shear stress (RSS) components are calculated as

$$
\tau_{i j}=-\rho \overline{u_{i}^{\prime} v_{j}^{\prime}}=\rho v_{t} \frac{d u_{i}}{d z}
$$

in which $\rho$ is the density of fluid, $v_{t}$ is the eddy viscosity, bar represents averaging over time and a prime denotes a fluctuating quantity in the laboratory frame of reference $(X, Y, Z)$. The RSS is scaled by the downstream averaged velocity $U_{d}^{2}$. The Reynolds shear stresses represent the transport of momentum that can be attributed to turbulence and are generally related to gradients of the base flow and depend on transport of the turbulence fluctuations from the entire flow field. Hence they can be correlated with accelerating and decelerating portions of the flow field. The time-averaged velocity gradient is responsible for generating turbulent shear stresses in the channel. Therefore, the shear layer is a site for turbulence production but the distributions of Reynolds shear stresses become particularly complex due to effect of secondary currents. Here, two runs are chosen to illustrate the difference of the Reynolds shear stress distributions. Velocity fluctuations and Reynolds shear stresses have a complex distribution along the streamwise direction in the shear layer. Values of Reynolds shear stress on the crosssections of the channel are found to depend on location, fluid density, and flow rate. Secondary flows are dominant in the near field region due to larger influence of streamline curvature. The formation of contraction and separation zones just downstream of the junction on the tailwater channel (discussed in 3.1) affects the magnitude of RSS in both channels. As mixing is enhanced, the strength of the separation zone is weakened. It is noticed that Reynolds shear stresses show a decrease with the increase of the discharge ratio. It is noted that the secondary currents are large enough and contribute significantly to the lateral transfer of momentum. As a consequence, they influence locally the values of the stress components $\tau_{Z X}^{*}$ and $\tau_{X Y}^{*}$.

The results show that the absolute values of two components of RSS $\tau_{Y Z}^{*}$ and $\tau_{Z X}^{*}$ are small compared to $\tau_{X Y}^{*}=$ $\overline{-u^{\prime} v^{\prime}}$. The vertical distributions of $\left(-\overline{\left.w^{\prime} u^{\prime}\right)}\right.$ in the shear layer are mainly due to the effect of secondary currents, and describe the intensity of vertical mixing between two merging streams near the downstream junction. The vertical gradients of $\tau_{Z X}=-\overline{w^{\prime} u^{\prime}}$ vary a great deal in the junction region and gradually level off at the far end of the channel. As the flow is almost uniform and strength of secondary currents is negligible at the far end, the flow behaves more like one in a simple rectangular channel. However, the value of $-\overline{u^{\prime} v^{\prime}}$ gives the indication of the strength of momentum exchange at the interface, since it is the velocity gradient $d u / d y$ which is associated with $-\overline{u^{\prime} v^{\prime}}$. RSS $\overline{-u^{\prime} v^{\prime}}$ tends to have a peak in the spanwise direction coinciding with the shear layer, with low values developed in regions close to the floodplain. In both cases, the peak value occurs at the top of surface, and then it decreases sharply in downstream directions almost linearly. Most researchers have assumed the peak to occur at this location due to momentum transfer between two converging flows. The maximum values of mean $\operatorname{RSS}\left(-\overline{w^{\prime} u^{\prime}}\right)$ are observed within the shear layer is 520 times higher than the values measured upstream of the confluence in both channels. However, outside this zone the RSS values are reduced and comparable to those observed in both channels upstream of the confluence. It is also found that the magnitude of $\overline{\rho u^{\prime} w^{\prime}}$ is seen to be $54 \%$ and $30 \%$ larger near the surface in compound channel junction than the simple channel junction for a given discharge ratio, 0.25 and 0.50 respectively. Both longitudinal and vertical RSS within the mixing region of compound channel junction are generally greater than those observed for a simple channel junction. Boyer et al [27] observed that the maximum values of mean Reynolds shear stresses $\left(-\rho u^{\prime} w^{\prime}\right)$ are occurred within the shear layer and increase in $-\rho u^{\prime} w^{\prime}$ inside this region becomes less important at higher flows when $Q_{r}$ is lower. The spatial distributions of Reynolds shear stress also play a major role to adequately describe the characteristics of flow that are useful for the prediction of sediment transport.

\subsection{Water surface profile}

For many practical problems, water-surface profiles computations may be required for steady and unsteady flows at open-channel networks. In the present study, the water surface has been mapped for five flow conditions (three in compound channel and two in simple channel). The results of the water surface elevation normalized by $h_{d}$. Laboratory experiments revealed that the presence of tributary creates a variability of flow depth and flow velocities. The interaction between the converging flows makes an increase in water

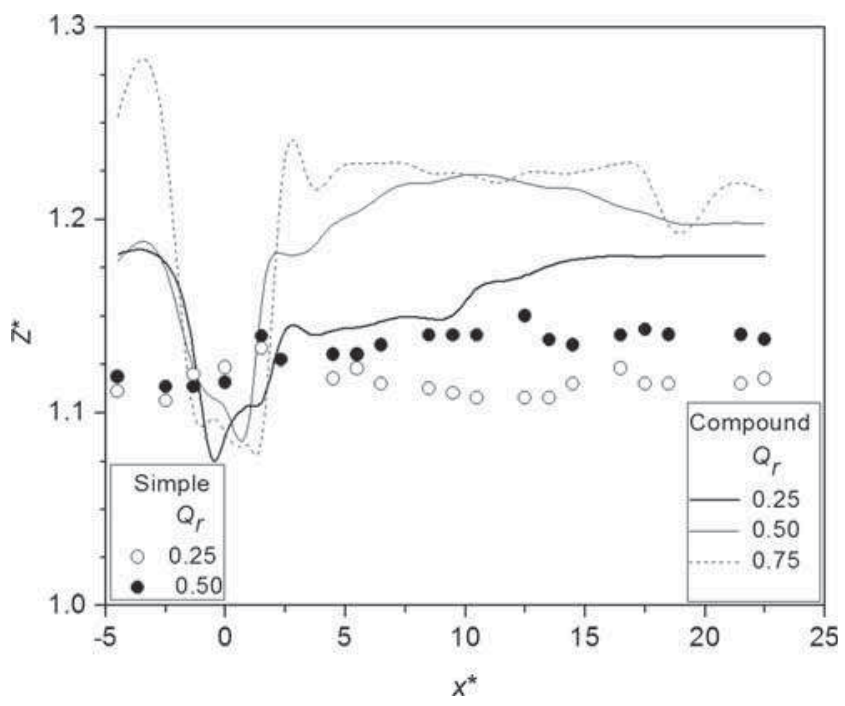

Figure 11. Variation of the water surface elevation along the flow direction. 

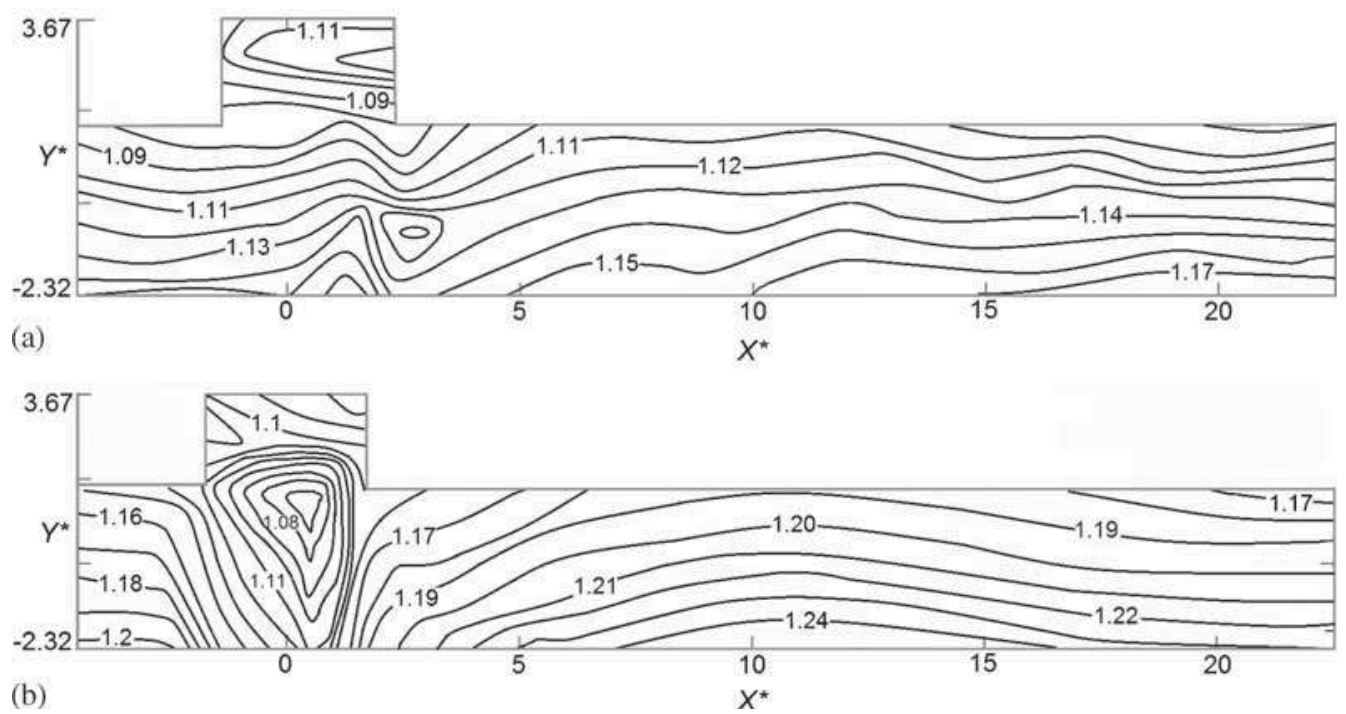

Figure 12. Water surface elevation for $Q_{r}=0.50$, (a) simple channel, (b) compound channel.

depth to a certain extent in the upstream of the mainstream (i.e. due to backwater effect) leading to flow deceleration and thus converting the fluid kinetic energy to potential energy. The tributary flow causes the mainstream flow to be entrained toward the opposite bank and generates an unstable separation streamline that changes its direction at the downstream corner of the junction. The flow depth in the tributary decreases as the upstream corner of the junction is approached and a drawdown is observed in the longitudinal profile as flow enters the contracted region. These observations agree with those of [14] and are attributed to low pressure in the separation zone, the extent of which increases as discharge ratio decreases.

The flow is separated just behind the junction and surface depression is observed in the separation zone. In the present study, a zone of depression in water level is prominent near the junction region at $X^{*}=0.34-0.66, Y^{*}=-0.5$ for all cases; however, such a phenomenon does not occur in the combining simple channel (figure 11). The streamline curvature gives rise to centrifugal acceleration across the flow and not along the vertical direction. This acceleration may change the depth of flow on both sides of the branch channel. It is clearly shown in figure 12 that the free surface has transverse slope around the junction close to the inner bank and is lower in level compared to the outer bank. This feature is similar to the free surface elevation on outer curve apex observed in the meandering channel. The difference in the water surface elevation across the junction decreases as discharge ratio, $Q_{\mathrm{r}}$ increases. It is seen that the surface elevation upstream of the compound channel junction is about $4.25 \%$ higher than that of downstream for the high discharge ratio while it is around $7.65 \%$ for the low discharge ratio. For low discharge ratio flows, more flow energy comes from tributary channel resulting in larger energy loss at the junction. It is also observed that the difference in water surface elevations at the upstream and downstream ends is comparatively smaller than that in simple channel. This pattern is more distinctive for flow conditions with smaller discharge ratio values within the separation and downstream sections of the branch channel. Results for simple channel are quite similar to those of [2]. Experimental observations show only a small difference in the depth of flow along the lateral wall except at the junction corner where the flow separates.

\section{Conclusions}

An experimental investigation for subcritical flow was carried out to emphasize the effect of discharge ratio on flow dynamics in a channel junction. Five flow ratios between the main and the tributary channel are studied in this paper and its influence on the mean and turbulent structure of the flow at a channel junction is discussed. A comparison between the results of the compound channel and the simple channel junctions is performed.

The following are the main conclusions of the present work:

- A separation zone is formed along the branch-side bank of the mainstream channel for all flow ratios. The geometry of separation zone depends on the discharge ratio and varies along the vertical plane with the largest size formed near the free surface. However, there is no marked separation zone formed at bed of the main channel.

- The shear layer developing at the interface between the confluent streams is highly affected by the tributary flow, the lateral mass exchange and the separation zone. Flow features around the junction rely on the strength of the secondary current, strengthening with a reduction in the discharge ratio. 
- The presence of separation zone affects the spatial distributions of RSS, especially near the interface boundary. The magnitude of the peak of time-averaged RSS is not always located at the junction; it is shifted towards the mainstream, when mass is transferred from the floodplain.

- A zone of depression in water level is created near the junction region for all compound channel experiments. However, such a zone does not occur in the simple channel junction.

- Overall, flow in a compound channel junction behaves similar to simple channel geometry except for small quantitative differences arising from a higher turbulence production.

The present study revealed that the physical model is quite useful in obtaining detailed flow field information. Particularly, it is valuable in understanding the flow feature changes due to change of some important flow parameters. Although this research relates to only one junction angle and to horizontal equal-width branches the present work may be considered a step towards the consistent investigation of combining junction flows. This study would also provide a link with other similar studies of supercritical flow and transcritical flow conditions in intersections.

\section{Nomenclature}

\begin{tabular}{|c|c|}
\hline$B$ & $\begin{array}{l}\text { Bottom width of the longitudinal and lateral } \\
\text { channel, } \mathrm{m}\end{array}$ \\
\hline$B_{f}$ & Width of flood plain, $\mathrm{m}$ \\
\hline$h$ & Flow depth in main channel, $\mathrm{m}$ \\
\hline$h_{\mathbf{f}}$ & Flow depth above the floodplain, $m$ \\
\hline$h_{d}$ & Flow depth at outlet, $\mathrm{m}$ \\
\hline$D_{r}$ & Depth ratio \\
\hline$g$ & Gravitational acceleration, $\mathrm{m} / \mathrm{s}^{2}$ \\
\hline$h$ & Bankfull depth, m \\
\hline$h_{d}$ & Flow depth at outlet, m \\
\hline$Q_{m}, Q_{t}$ & $\begin{array}{l}\text { Inflow discharges in mainstream, and tributary } \\
\text { channel, } \mathrm{m}^{3} / \mathrm{s}\end{array}$ \\
\hline$Q_{d}$ & Discharge at the outlet of main channel, $\mathrm{m}^{3} / \mathrm{s}$ \\
\hline$Q_{r}$ & Discharge ratio $\left(\frac{Q_{m}}{Q_{d}}\right)$ \\
\hline$F_{r}$ & Froude number \\
\hline $\mathrm{R}_{\mathrm{e}}$ & Reynolds number \\
\hline$S_{i}$ & Shape index \\
\hline$U_{d}$ & $\begin{array}{l}\text { Average cross-sectional velocity at the outlet, } \\
\mathrm{m} / \mathrm{s}\end{array}$ \\
\hline$V s$ & Magnitude of secondary current, m/s \\
\hline$u, v, w$ & $\begin{array}{l}\text { Time-averaged velocities in } X, Y \text { and } Z \\
\text { directions, } \mathrm{m} / \mathrm{s}\end{array}$ \\
\hline$u^{*}, v^{*}, w^{*}$ & Non-dimensional $u, v, w$ \\
\hline$X, Y, Z$ & Space coordinates \\
\hline$X^{*}, Y^{*}, Z^{*}$ & Non-dimensional space coordinates. \\
\hline
\end{tabular}

Greek symbols

$\begin{array}{ll}\rho & \text { Density of fluid, } \mathrm{Kg} / \mathrm{m}^{3} \\ \tau_{i j} & \text { Reynolds shear stress, N/m } \mathrm{m}^{2} \\ v_{t} & \text { Eddy viscosity, } \mathrm{m}^{2} / \mathrm{s}\end{array}$

\section{References}

[1] Gurram S K, Karki K S and Hager W H 1997 Subcritical junction flow. J. Hydraul. Eng. 123(5): 447-455

[2] Huang J, Larry J W and Yong G L 2002 Three-Dimensional Numerical study of flows in open channel junction. $J$. Hydraul. Eng. 128(3): 268-280

[3] Taylor E H 1944 Flow characteristics at rectangular open channel junctions. Trans. Am. Soc. Civ. Eng. 109: 893-912

[4] Webber N B and Greated C A 1966 An investigation of flow behavior at the junction of rectangular channels. Proceedings of Institute Civil Engineers Vol. 34, London, 321-334

[5] Hager W H 1989 Transitional flow in channel junctions. $J$. Hydraul. Eng. 115(2): 243-259

[6] Hsu C C, Lee W J and Chang C H 1998a Subcritical open channel junction flow. J. Hydraul. Eng. 124(8): 847-855

[7] Ramamurthy A S, Carballada L B and Tran D M 1988 Combining open-channel flow at right-angeled junctions. $J$. Hydraul. Eng. ASCE 114(12): 1449-1460

[8] Shabayek S, Steffler P and Hicks F 2002 Dynamic model for subcritical combining flows in channel junctions. J. Hydraul. Eng. 128(9): 821-828

[9] Bradbrook K F, Biron P M, Lane S N, Richards K S and Roy A G 1998 Investigation of controls on secondary circulation in a simple confluence geometry using a three-dimensional numerical model. Hydrol. Process. 12: 1371-1396

[10] Biron P M, Richer A, Kirkbride A D, Roy A G and Han S 2002 Spatial patterns of water surface topography at a river confluence. Earth Surf. Processes Landforms 27: 913-928, doi: 10.1002/esp.359

[11] Bradbrook K F, Lane S N, Richards K S, Biron P M and Roy A G 2001 Role of bed discordance at asymmetrical open-channel confluences. J. Hydraul. Eng. 127: 351-368, doi: 10.1061/(ASCE)0733-9429(2001)127: $5(351)$

[12] Lane S N, Bradbrook K F, Richards K S, Biron P M and Roy A G 1999b Time averaged flow structure in the central region of a stream confluence: A discussion. Earth Surf. Process. Landforms 24: 361-367

[13] Zhang Ting, Xu Wei-Lin and Wu Chao 2009 Effect of discharge ratio on flow characteristics in $90^{\circ}$ equal width open-channel junction. J. Hydrodyn. 21(4): 541-549

[14] Weber L J, Schumate E D and Mawer N 2001 Experiments on flow at $90^{\circ}$ open channel junction. J. Hydraul. Eng. 127(5): 340-350

[15] Ghostine R, Kesserwani G, Mose R, Vazquez J, Ghenaim A and Gregoire C 2009 A confrontation of 1D and 2D RKDG numerical simulation of transitional flow at open channel junction. Int. J. Numer. Meth. Fluids 61: 752-767

[16] Ghostine R, Mose R, Vazquez J, Ghenaim A and Grégoire C 2010 Two-dimensional simulation of subcritical flow at a combining junction: Luxury or necessity? J. Hydraul. Eng. 136(10): 799-805 
[17] Ghostine R, Vazquez J, Terfous A, Mose R and Ghenaim A 2012 Comparative study of $1 \mathrm{D}$ and 2D flow simulations at open-channel junctions. J. Hydraul. Res. 50(2): 164170

[18] Zeng C and Li C W 2010 A hybrid RANS-LES model for combining flows in open channel T-junctions. J. Hydrodyn. 22(5): 154-159

[19] Goudarzizadeh R, Mousavi J S H and Hedayat N 2010 Simulation of 3D flow using numerical model at open-channel confluences. World Acad. Sci., Eng. Tech. 71: 650-655

[20] Goudarzizadeh R, Mousavi J S H, Hedayat N and Naghshineh M H 2011 Numerical investigation of the flow separation zone and quality of the bed shear stress distribution at open-channel confluences. World Acad. Sci. Eng. Tech. 73: 968-971

[21] Best J L and Reid I 1984 Separation zone at openchannel junctions. J. Hydraul. Eng 110: 1588-1594, doi: 10.1061/(ASCE)0733-9429(1984)110:11(1588)

[22] Best J L 1987 Flow dynamics at river channel confluences: Implications for sediment transport and bed morphology, Recent Developments in Fluvial Sedimentology. Spec. Publ. SEPM Soc. Sediment. Geol. 39: 27-35

[23] Biron P M, Roy A G, Best J L and Boyer C J 1993b Bed morphology and sedimentology at the confluence of unequal depth channels. Geomorphology 8: 115-129, doi: 10.1016/0169-555X(93)90032-W

[24] Biron P M, Best J L and Roy A G 1996a Effects of bed discordance on flow dynamics at open channel confluences. J. Hydraul. Eng. 122: 676-682, doi: 10.1061/(ASCE)0733-9429(1996)122:12(676)

[25] Biron P M, Ramamurthy A S and Han S 2004 Threedimensional numerical modeling of mixing at river confluences. J. Hydraul. Eng. 130: 243-253

[26] Gaudet J M and Roy A G 1995 Effect of bed morphology on flow mixing length at river confluences. Nature 373: 138139

[27] Boyer C, Roy A G and Best J L 2006 Dynamics of a river channel confluence with discordant beds: Flow turbulence, bed load sediment transport, and bed morphology. J. Geophys. Res. 111: F04007, doi: 10.1029/2005JF000458

[28] Rhoads B L and Kenworthy S T 1998 Time-averaged flow structure in the central region of a stream confluence. Earth Surf. Process. Landforms 23: 171-191, doi: 10.1002/(SICI)1096-9837(199802)

[29] Rhoads B I and Sukhodolov A N 2001 Field investigation of three dimensional flow structure at stream confluences. Water Resour. Res. 37(9): 2393-2410
[30] Hager W H and Schwalt M 1995 Experiments to supercritical junction flow. Exp. Fluids 18(6): 429-437

[31] Liu T H 2005 Experimental study on hydrodynamic characteristics and sediment motion at mountain confluence River. MPhil thesis, Sichuan University, China

[32] Wang X K, Wang X Y, Lu W Z and Liu T H 2006 Experimental study on flow structure at open channel confluences. $J$. Sichuan Univ. 38(2): 1-5

[33] Mignot E, Rivie're N, Perkins R and Paquier A 2008b Flow patterns in a four branches junction with supercritical flow. $J$. Hydraul. Eng. 134(6): 701-713

[34] Yang Q Y and Wang X K 2009 Experimental study on characteristic of separation zone in confluence zones in river. $J$. Hydrol. Eng. 14(2): 166-171

[35] Riviere N, Travin G and Perkins R J 2011 Subcritical open channel flows in four branch intersections. Water Resour. Res. 47(10): W10517

[36] WAVO 2005 WAVO MK IV User's guide. Float type water level follower, WL Delft Hydraulics, Delft, The Netherlands

[37] Modi P N, Ariel P D and Dandekar M M 1981 Conformal mapping for channel junction flow. J. Hydraul. Div. 107: 1713-1733

[38] Sukhodolov A N and Rhoads B L 2001 Field investigation of three-dimensional flow structure at stream confluences 2 . Turbulence. Water Resour. Res. 37: 2411-2424

[39] Bradbrook K F, Lane S N and Richards K S 2000a Numerical simulation of three dimensional, time-averaged flow structure at river channel confluences. Water Resour. Res. 36: 27312746

[40] Blanckaert K, Duarte A and Schleiss A J 2010 Influence of shallowness, bank inclination and bank roughness on the variability of flow patterns and boundary shear stress due to secondary currents in straight open-channels. Adv. Water Resour. 33(9): 1062-1074

[41] McLelland S J, Ashworth P J and Best J L 1996 The origin and downstream development of coherent flow structures at channel junctions. In: Ashworth P J et al (eds.) Coherent flow structures in open channels. pp. 459-490, John Wiley, Chichester, UK

[42] De Serres B, Roy A G, Biron P M and Best J L 1999 Threedimensional structure of flow at a confluence of river channels with discordant beds. Geomorphology 26: 313-335

[43] Nezu I, Nakagawa H and Rodi W 1989 Significant difference of secondary currents in closed channels and narrow open channels. Proceedings of $23^{\text {rd }}$ Congress IAHR, Ottawa, Canada, A125-A132 